Article type : Research Article

\title{
Design, synthesis, and biological evaluation of a new class of benzo[b]furan derivatives as antiproliferative agents, with in silico predicted antitubulin activity
}

Antonino Lauria ${ }^{\mathrm{a}}$, Carla Gentile ${ }^{\mathrm{a}}$, Francesco Mingoia ${ }^{\mathrm{b}}$, Antonio Palumbo Piccionello ${ }^{\mathrm{a}}$, Roberta Bartolotta $^{\mathrm{a}}$, Riccardo Delisi $^{\mathrm{a}, \mathrm{b}}$, , Silvestre Buscemi $^{\mathrm{a}}$, Annamaria Martorana $^{\mathrm{a}, *}$

a'Dipartimento di Scienze e Tecnologie Biologiche Chimiche e Farmaceutiche "STEBICEF"Università di Palermo, Via Archirafi 32 -90123 Palermo, Italy.

' Istituto per lo Studio dei Materiali Nanostrutturati, (ISMN), Consiglio nazionale delle Ricerche (CNR), Via U. La Malfa 153 - 90146 Palermo, Italy.

Corresponding Author:

Dr Annamaria Martorana

Via Archirafi 32, - 90123 Palermo (Italy)

Email_Address: annamaria.martorana@unipa.it

This article has been accepted for publication and undergone full peer review but has not been through the copyediting, typesetting, pagination and proofreading process, which may lead to differences between this version and the Version of Record. Please cite this article as doi: 10.1111/cbdd.13052

This article is protected by copyright. All rights reserved. 

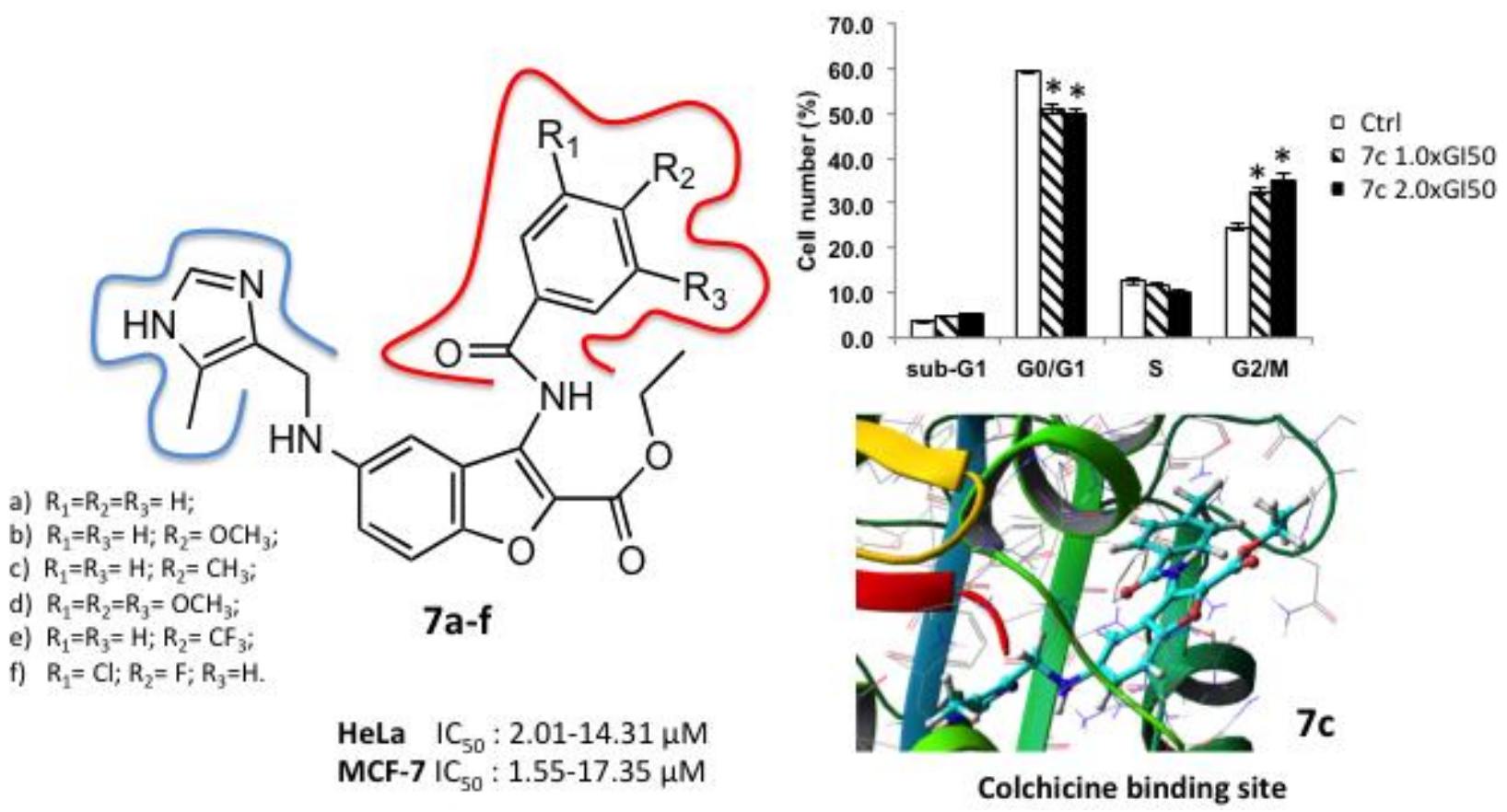

A new series of 3-benzoylamino-5-(1H-imidazol-4-yl)methylaminobenzo[ $b]$ furans were synthesized and screened as antitumor agents. The MTT test (HeLa and MCF-7) underlined a significant growth inhibition effect of the derivatives 7a-f. Compounds $\mathbf{7 b - d , f}$, tested in cell cycle perturbation experiments on HeLa cells produced a cell cycle arrest in G2/M phase. In addition, the structure similarity of these benzo[b]furans with known colchicine binding sites binders led us to investigate their potent interference with the microtubule system by computational analysis as a support of the observed biological effects.

\section{Design, synthesis, and biological evaluation of a new class of benzo[b]furan derivatives as antiproliferative agents, with in silico predicted antitubulin activity}

Running title:

\section{Benzo $[b]$ furan derivatives with antiproliferative activity}

Antonino Lauria ${ }^{\mathrm{a}}$, Carla Gentile ${ }^{\mathrm{a}}$, Francesco Mingoia ${ }^{\mathrm{b}}$, Antonio Palumbo Piccionello ${ }^{\mathrm{a}}$, Roberta Bartolotta $^{\mathrm{a}}$, Riccardo Delisi ${ }^{\mathrm{a}, \mathrm{b}}$, Silvestre Buscemi ${ }^{\mathrm{a}}$, Annamaria Martorana ${ }^{\mathrm{a}, *}$

aDipartimento di Scienze e Tecnologie Biologiche Chimiche e Farmaceutiche "STEBICEF"Università di Palermo, Via Archirafi 32 -90123 Palermo, Italy.

This article is protected by copyright. All rights reserved. 
${ }^{\mathrm{b}}$ Istituto per lo Studio dei Materiali Nanostrutturati, (ISMN), Consiglio nazionale delle Ricerche (CNR), Via U. La Malfa 153 - 90146 Palermo, Italy.

Corresponding Author:

Dr Annamaria Martorana

Via Archirafi 32, - 90123 Palermo (Italy)

Email_Address: annamaria.martorana@unipa.it

Tel: $\quad+39-091-2389-6821$

\begin{abstract}
A new series of 3-benzoylamino-5-(1H-imidazol-4-yl)methylaminobenzo[ $b]$ furans were synthesized and screened as antitumor agents. As a general trend, tested compounds showed concentration-dependent antiproliferative activity against HeLa and MCF-7 cancer cell lines, exhibiting $\mathrm{GI}_{50}$ values in the low micromolar range. In most cases, insertion of a methyl substituent on the imidazole moiety improved the antiproliferative activity. Therefore, methyl-imidazolyl-benzo[b]furans compounds were tested in cell cycle perturbation experiments, producing cell cycle arrest with proapoptotic effects. Their core similarity to known colchicine binding site binders led us to further study the structure features as antitubulin agents by in silico protocols.
\end{abstract}

\title{
KEYWORDS
}

3-benzoylamino-5-(1H-imidazol-4-yl)methylaminobenzo[b]furans, antitumor agents, HeLa and MCF-7 cell lines, G2/M phase, colchicine binding site, VLAK protocol, induced fit docking studies, antitubulin agents.

The discovery of more potent, clinically safe, and commercially attractive new targeted drugs is the driving force at the base of medicinal chemistry research. Since a long time, our research work focused the attention on the design, synthesis, and biological evaluation of new heterocyclic compounds able to halt tumor cell proliferation (Figure 1 compounds 1-4). ${ }^{[1-4]}$

This article is protected by copyright. All rights reserved. 


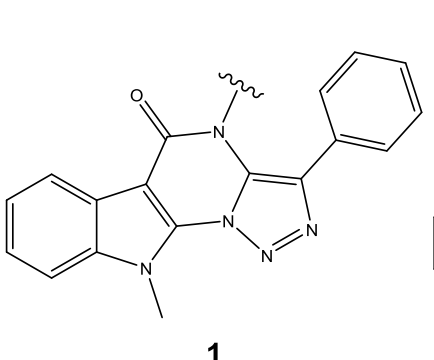

1

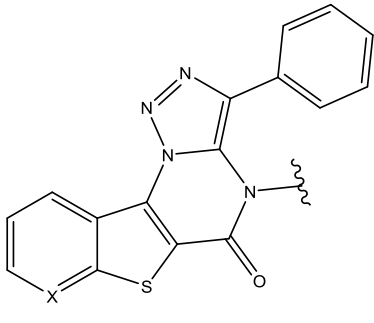

2

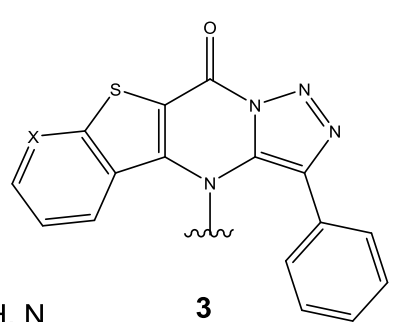

$\mathrm{X}=\mathrm{CH}, \mathrm{N}$

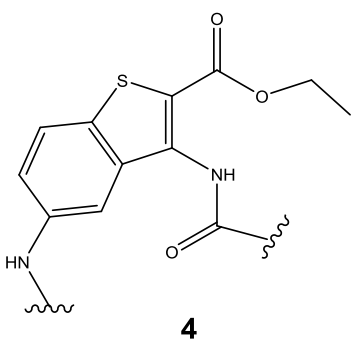

4

FIGURE 1.

In silico approach, performed through the Virtual Lock-and-Key (VLAK) protocol, ${ }^{[5]}$ allowed us to select new annelated thieno- series of type 2, 3 and $\mathbf{4}$ as novel antitumor agents (Figure 1). ${ }^{[6]}$ These compounds, featured by a sulfur atom in the scaffold and functionalized with suitable side chains, similar to that used for the precursor series $1,{ }^{[1]}$ demonstrated in vitro antiproliferative activity, exhibiting very low toxicity and high potency. ${ }^{[7-9]}$

Therefore, as a part of our ongoing search for biologically active small molecules, keeping our attention on heterocyclic ring systems, herein, we propose the synthesis, the biological screening, and the in silico insights of a new series of benzo[b]furan derivatives $\mathbf{5}, \mathbf{6}$, and $\mathbf{7}$ (Figure 2).

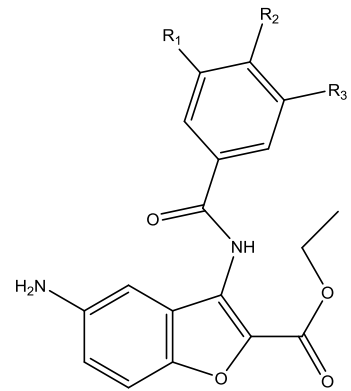

5

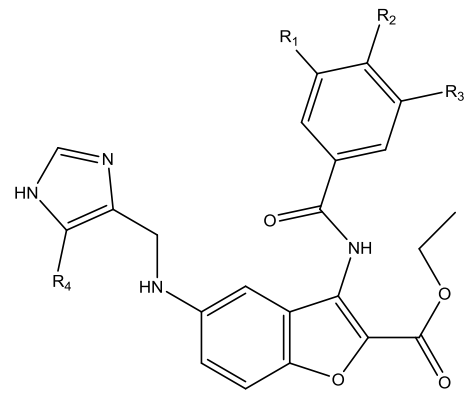

6) $\mathrm{R}_{4}=\mathrm{H}$
7) $\mathrm{R}_{4}=\mathrm{CH}_{3}$

\section{FIGURE 2.}

The pharmaceutical interest toward these new molecules is supported by several experimental data described in literature, ${ }^{[10]}$ which assigned to the benzo[b]furan scaffold peculiar biological activities. Romagnoli and co-workers reported an interesting series of 3arylaminobenzo[b]furans $\mathbf{8}$ as result of accurate structure-activity relationships (SAR) studies. ${ }^{[11]}$ These compounds, acting on the colchicine binding site of tubulin, showed high antiproliferative activity, comparable to that of the thiophene derivatives 9a,b (Figure 3). ${ }^{[12]}$ 

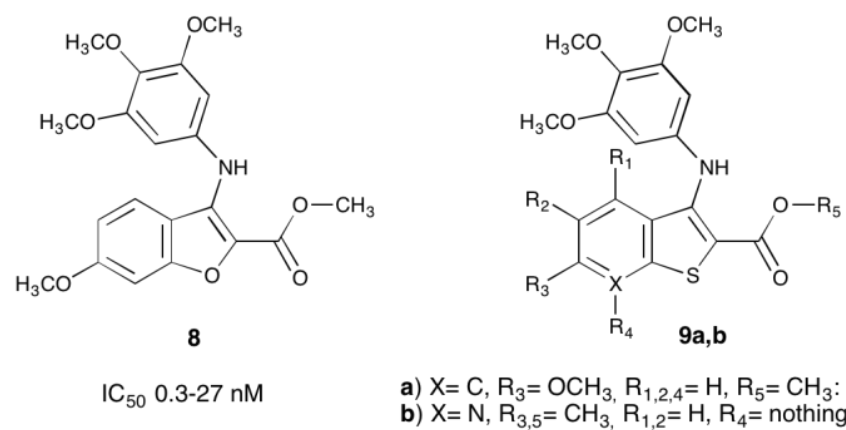

a) $\mathrm{X}=\mathrm{C}, \mathrm{R}_{3}=\mathrm{OCH}_{3}, \mathrm{R}_{1,2,4}=\mathrm{H}, \mathrm{R}_{5}=\mathrm{CH}_{3}: \mathrm{IC}_{50}$ 0.3-10.3 nM;

b) $X=N, R_{3,5}=C_{3}, R_{1,2}=H, R_{4}=$ nothing: IC $I_{50} 0.2-16.2 \mathrm{nM}$.

\section{FIGURE 3.}

\section{EXPERIMENTAL SECTION}

\subsection{Chemistry}

Compounds 5-7 were completely characterized in terms of mp, ${ }^{1} \mathrm{H}$ and ${ }^{13} \mathrm{C}$ NMR, IR and HRMS. Full details of the syntheses are provided in the SI. Unless otherwise indicated, all reagents and solvents were purchased from commercial sources and used without further purification. All melting points $\left({ }^{\circ} \mathrm{C}\right)$ were determined on a Büchi Tottoli capillary apparatus and are uncorrected; IR spectra were determined in bromoform with a Jasco FT/IR 5300 spectrophotometer. ${ }^{1} \mathrm{H}$ NMR, ${ }^{13} \mathrm{C}$ NMR spectra were respectively recorded, at 200 and 50.3 $\mathrm{MHz}$ in $\mathrm{CDCl}_{3}$ or DMSO-d6 solution, using a Bruker AC-E series $200 \mathrm{MHz}$ spectrometer. Chemical shifts values are given in $\mathrm{ppm}$ and referred as the internal standard to tetramethylsilane (TMS). The following abbreviations are used: brs= broad signal, $s=$ singlet, $\mathrm{d}=$ doublet, $\mathrm{t}=$ triplet, $\mathrm{q}=$ quartet, $\mathrm{m}=$ multiplet. The purity of all compounds screened in biological assays was determined to be $>95 \%$ by HPLC/MS analysis. HRMS were obtained on an Agilent 6540 UHD accurate-mass Q-TOF spectrometer equipped with a Dual AJS ESI source working in positive mode. Microanalyses were in agreement with theoretical values \pm $0.4 \%$. Thin layer chromatography was performed on precoated $(0.25 \mathrm{~mm})$ silica gel GF254 plates, compounds were detected with a $254 \mathrm{~nm}$ UV lamp. Column chromatography was performed with Merck silica gel ASTM (230 and 400 mesh), or with a Biotage FLASH40i chromatography module (prepacked cartridge system). 2-fluorobenzonitrile (10) is commercially available. 5-nitro-2-fluorobenzonitrile (11) was obtained following the procedure reported in literature. ${ }^{[13]}$

\subsubsection{Synthesis of ethyl 3-amino-5-nitro-benzo[b]furan-2-carboxylate 12}

To a solution of 2-fluoro-5-nitrobenzonitrile (11) (0.3 g, $1.8 \mathrm{mmol})$ in dry DMF (5 mL), ethyl glycolate $(0.3 \mathrm{~mL}, 3.2 \mathrm{mmol})$ and potassium carbonate $(0.95 \mathrm{~g}, 6.8 \mathrm{mmol})$ were added at room temperature, and the mixture was heated at $100^{\circ} \mathrm{C}$ for $12 \mathrm{~h}$. After the reaction was

This article is protected by copyright. All rights reserved. 
completed, the reaction mixture was cooled and poured in water/ice. The precipitate was collected by filtration and dried to give orange-red needles of $\mathbf{1 2}$.

\subsubsection{General procedure for the synthesis of ethyl 3-benzoylamino-5- nitrobenzo[b]furan-2-carboxylates 14a-f}

To a suspension of amine $12(92 \mathrm{mg}, 0.37 \mathrm{mmol})$ and pyridine $(0.56 \mathrm{mmol})$ was added the appropriate benzoyl chloride $13(0.56 \mathrm{mmol})$. The reaction mixture was stirred at room temperature over about $12 \mathrm{~h}$, and then poured onto stirred water/ice. The precipitate was collected by filtration, dried overnight. The crude was crystallized from ethyl acetate.

\subsubsection{General procedure for the synthesis of ethyl 5-amino-3-benzoylamino- benzo[b]furan-2-carboxylates 5a-f}

A suspension of 5-nitro compound 14a-f $(1 \mathrm{mmol}), 10 \% \mathrm{Pd} / \mathrm{C}(0.05 \mathrm{~g})$ in ethanol was subjected to hydrogenation using a Parr Hydrogenation apparatus at 500 psi for $2 \mathrm{~h}$. The catalyst was removed by filtration and the filtrate was concentrated under reduced pressure. The crude was crystallized from ethanol.

\subsubsection{General procedure for the synthesis of ethyl 3-benzoylamino-5-[(1H-imidazolyl-} 4-yl-methyl)-amino]-benzo[b]furan-2-carboxylates 6a-f and 7a-f

To a suspension of the 5a-f $(1.25 \mathrm{mmol})$ and the appropriate aldehyde $\mathbf{1 5}(1.6 \mathrm{mmol})$ in dry ethanol $(10 \mathrm{~mL})$ was added acetic acid up to $\mathrm{pH} 4$. The mixture was stirred for $30 \mathrm{~min}$, and then $\mathrm{NaBH}_{3} \mathrm{CN}(1.6 \mathrm{mmol})$ was added continuing the stirring at room temperature for further 6-24h. The reaction solvent was removed under reduced pressure and the crude product was purified by chromatography column using dichloromethane/methanol 98:2 as eluent. Recrystallization from ethanol. In the reactions for the synthesis of the methyl-imidazolyl side-chain compounds 7a-f, it was possible to isolate derivative $\mathbf{1 6}$ in variable yields (10$23 \%)$.

\subsection{Biology}

Propidium iodide, ribonuclease A (RNAse A), 3-(4,5-dimethyl-2-thiazolyl)-2,5-diphenyl-2Htetrazolium bromide (MTT), and DMSO were obtained from Sigma Aldrich (St. Louis, MO, USA). RPMI, fetal bovine serum (FBS), phosphate buffered saline (PBS), L-glutamine solution $(200 \mathrm{mM})$, trypsin-EDTA solution (170.000 U/l trypsin and $0.2 \mathrm{~g} / \mathrm{l}$ EDTA) and penicillin-streptomycin solution $(10.000 \mathrm{U} / \mathrm{ml}$ penicillin and $10 \mathrm{mg} / \mathrm{ml}$ streptomycin) were purchased from Lonza (Verviers, Belgium).

\subsubsection{Cell culture}

The tumor cell lines HeLa (human epithelial cervical cancer) and MCF-7 (human epithelial breast cancer), were obtained from American Type Culture Collection (ATCC) (Rockville, 
MD, USA). The cells were cultured as monolayers and maintained in a humidified atmosphere with $5 \% \mathrm{CO}_{2}$ at $37^{\circ} \mathrm{C}$. MCF-7 cells were grown in DMEM while HeLa cells in RPMI. Both medium were supplemented with 5\% FBS, $2 \mathrm{mM}$ L-glutamine, $50 \mathrm{IU} / \mathrm{ml}$ penicillin, and $50 \mu \mathrm{g} / \mathrm{ml}$ streptomycin. The cells were routinely cultured in $75 \mathrm{~cm}^{2}$ culture flasks and were trypsinized using trypsin-EDTA when the cells reached approximately $80 \%$ confluence. Exponentially growing cells were used for experiments.

\subsubsection{Antiproliferative Evaluation Assay}

Antiproliferative activity of 3-benzoylamino-benzo $[b]$ furan derivatives 5a-f, 6a-f and 7a-f was evaluated by MTT assay against HeLa and MCF-7 tumor cell lines. . The MTT assay is based on the protocol first described by Mossmann. ${ }^{[14]}$ It is a measurement of cell metabolic activity, and correlates quite well with cell proliferation. The assay was performed as previously described. ${ }^{[9]}$

\subsubsection{Cell-cycle analysis}

Effects of the 3-benzoylamino-benzo $[b]$ furan derivatives 7a-f exposure on cell-cycle were evaluated by DNA staining with propidium iodide and flow cytometry analysis. HeLa cells were seeded on 6 well plates at a density of 130000 cells/well, and treated 24 hours after seeding with or without various concentrations of test compounds. Following the treatments, cells were collected, washed in PBS, fixed in ice-cold $70 \%$ ethanol and kept at $-20^{\circ} \mathrm{C}$. Fixed cells were centrifuged, resuspended in PBS and stained with staining solution $(20 \mu \mathrm{g} / \mathrm{ml}$ propidium iodide, $200 \mu \mathrm{g} / \mathrm{ml}$ RNAse A and Triton X-100 in PBS). for $30 \mathrm{~min}$ at $37^{\circ} \mathrm{C}$. The DNA contents of more than 10000 cells were subjected to fluorescence-activated cell sorting (FACS) analysis (Coulter ${ }^{\circledR}$ Epics $^{\circledR} \mathrm{XL}^{\mathrm{TM}}$, Beckman) and the percentage of cells belonging to the different compartments of the cell cycle was determined. All experiments were performed in duplicate and reproduced at least two times.

\subsection{In silico studies}

The structure similarity of the benzo[b]furans 6 and 7 with colchicine binding site binders ${ }^{[11]}$ and the evidence of cell cycle arrest in G2/M phase, that is known to be a characteristic of these ligands, led to approach the in silico methods by two ways: the VLAK approach, a ligand based method developed by us, and the IFD (Induced Fit Docking), a structure based one.

This article is protected by copyright. All rights reserved. 


\section{VLAK protocol: ${ }^{[5]}$}

The protocol, described in supporting information, start to define the "lock model" for the studied target. A set of 5 ligands known colchicine binding site binders was selected (Figure $4)$.

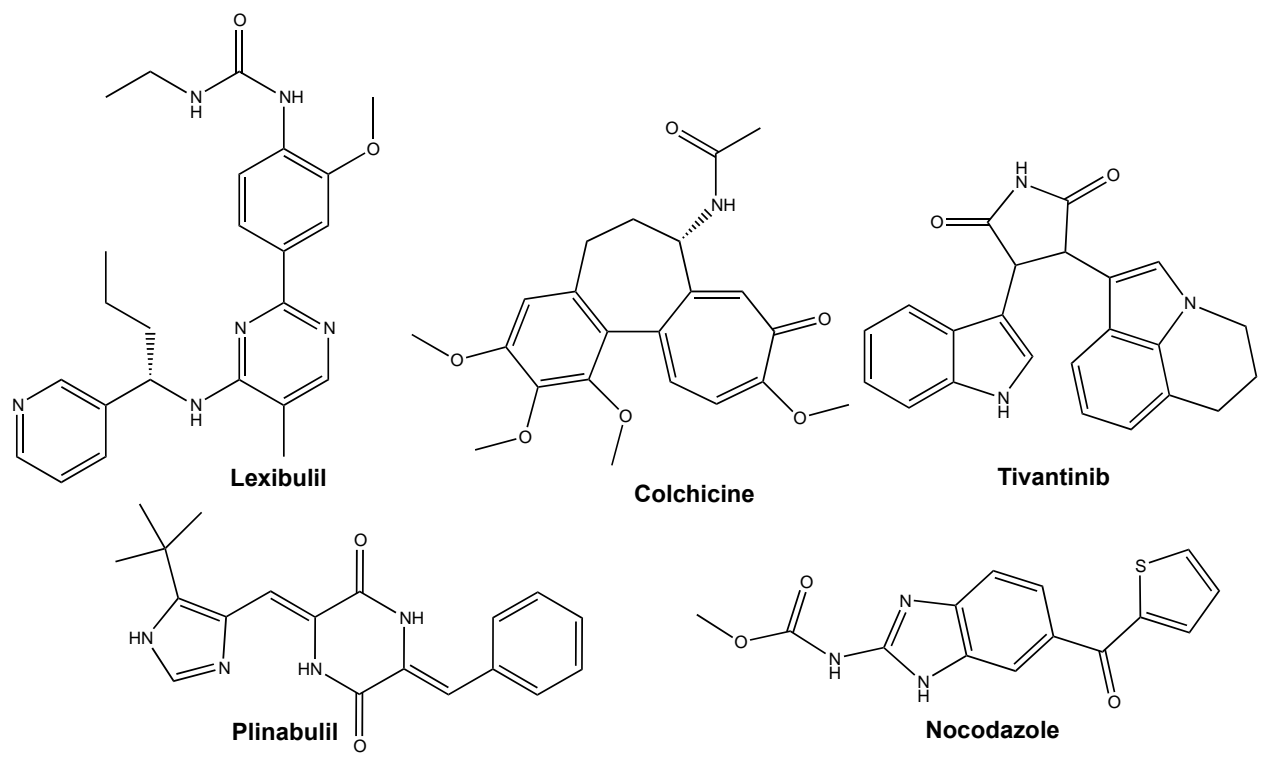

FIGURE 4.

The "lock model" was used as template in the virtual screening of the title compounds. At the end the affinity score (A\%) to each tested compound is assigned. As reported in Table 1 the A\% values are in the range $0.63-0.87$, assigning them a quite good affinity to colchicine binding site.

Table 1.

\begin{tabular}{cc|cc}
\hline Cmd & $\mathrm{A} \%$ & $\mathrm{Cmd}$ & $\mathrm{A} \%$ \\
\hline $\mathbf{6 a}$ & 0.63 & $\mathbf{7 a}$ & 0.57 \\
$\mathbf{6 b}$ & 0.70 & $\mathbf{7 b}$ & 0.64 \\
$\mathbf{6 c}$ & 0.73 & $\mathbf{7 c}$ & 0.77 \\
$\mathbf{6 d}$ & 0.87 & $\mathbf{7 d}$ & 0.63 \\
$\mathbf{6 e}$ & 0.62 & $\mathbf{7 e}$ & 0.59 \\
$\mathbf{6 f}$ & 0.64 & $\mathbf{7 f}$ & 0.64 \\
\hline
\end{tabular}

Induced fit docking (IFD): ${ }^{[15-17]}$

The crystal structure of colchicine-bound tubulin was downloaded from the PDB database (PDB code: 4O2B) and the tubulin dimer with bound colchicine (chains A and B) was extracted from the protein model. The protein was edited using Schrödinger protein preparation wizard, by adding of hydrogen for protonation of its ionisable residues, 
modification of tautomeric forms and repositioning of reorientable hydrogen to yield the optimized protein-ligand complex. All the synthesized derivatives were drawn using ChemDraw. The geometry was optimized by adding hydrogen atoms, generating ionization states, neutralizing the charged groups, generating tautomers, and low-energy ring conformers. The energy minimized structures were further used for IFD. Moreover the crystallized ligand colchicine was re-docked with the aim to evaluate the ability of IFD protocol to reproduce the experimental conformation (RMSD $=1.5 \AA$ ).

\section{RESULTS AND DISCUSSION}

\subsection{Chemistry}

In Scheme 1 is reported the general synthetic route for the preparation of 3-benzoyl-aminobenzo[b]furan derivatives 5-7.

1) preparation of the benzofuran core: the 2-fluoro-5-nitrobenzonitrile (11) was obtained through nitration of (10), using a mixture of concentrated nitric and sulfuric acids, under inert atmosphere. ${ }^{[13]}$ The reactivity of the ortho-fluorine atom on substrate (11) is improved by the nearby presence of both cyano and nitro substituents, leading to nucleophilic displacement by ethyl glycolate, in the presence of $\mathrm{K}_{2} \mathrm{CO}_{3}$ and $\mathrm{N}$,N-dimethyl-formamide (DMF). The following in situ intramolecular cyclization brought about the formation benzo[ $b]$ furan central core, allowing isolation of the 3-amino-benzo[b]furan derivative $\mathbf{1 2}$.

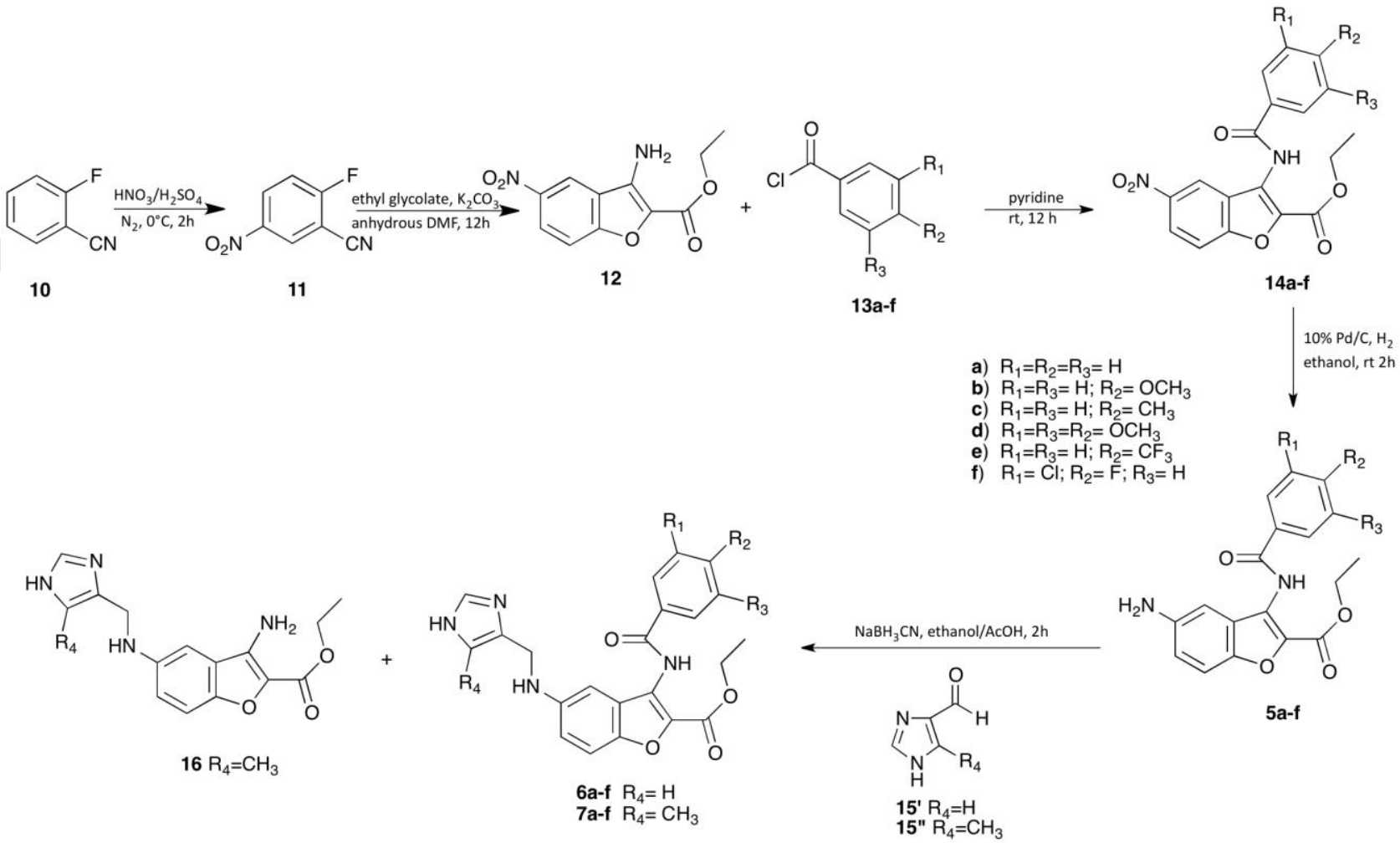

This article is protected by copyright. All rights reserved. 


\section{SCHEME 1.}

2) amide bond formation at $\mathrm{C} 3$ position: in order to insert the benzoyl moiety, the key intermediate 3-amino-benzo[b]furan 12 was treated with benzoyl chlorides 13a-f substituted with electron-withdrawing and electron-releasing groups. The nucleophilic acyl substitution was carried out employing pyridine both as base and solvent. The use of other reaction media gave a significant decrease of the yields.

3) $\mathrm{NO}_{2}$ reduction: nitro group reduction on derivatives 14a-f was performed by hydrogenation with $10 \% \mathrm{Pd} / \mathrm{C}$ in ethanol, leading to the 5-amino-benzo[b]furans 5a-f.

4) imidazolyl moiety installation: in the end, the isolation of ethyl 3-benzoylamino-5-[(1Himidazolyl-4-yl-methyl)-amino]-benzo[b]furan-2-carboxylates 6a-f and 7a-f was achieved through a reductive amination with imidazole-4-carbaldehydes $\mathbf{1 5}$ and sodium cyanoborohydride, as selective reducing agent. In this synthetic step, when the carbaldehyde 15" was used, it was possible to isolate compound $\mathbf{1 6}$, where hydrolysis of the amide function was observed.

\subsection{Biology}

\subsubsection{Antiproliferative activity}

The antiproliferative activity of the synthesized 3-benzoylamino-benzo[b]furan derivatives 5a-f, 6a-f, and 7a-f was evaluated on HeLa and MCF-7 tumour cell lines for 48h, using MTT based cell viability assay. In Table 2 were displayed the $\mathrm{GI}_{50}$ values of all tested compounds, which, for an easier analysis, were divided into three main subgroups: 5-aminobenzo $[b]$ furans 5a-f, imidazolyl side-chain compounds 6a-f, and methyl-imidazolyl sidechain derivatives 7a-f. The 5-amino-benzo[b]furan compounds 5a-f were not active or showed low activity, with $\mathrm{GI}_{50}$ values higher than $30 \mu \mathrm{M}$.

This article is protected by copyright. All rights reserved. 


\begin{tabular}{l|lll|l|l|l|}
\hline & & & \\
\end{tabular}

As clearly highlighted by the data reported in Table 2, the insertion of the imidazolyl- side chain moiety exerted a weighty influence on the antiproliferative activity. In fact, with the exception of derivatives $6 \mathbf{a}$ and $\mathbf{6 e}$, where the benzoyl moiety is respectively unsubstituted or bears a 4-trifluoromethyl substituent, the inhibition growth activity of benzo[ $b]$ furan compounds of type $\mathbf{6}$ were promising, showing $\mathrm{GI}_{50}$ values in the low micromolar range. Within this subgroup, remarkable was the activity of the 3,4,5-trimethoxy-benzoylbenzo[b]furan $\mathbf{6 d}$ on MCF-7 cell line, with a $\mathrm{GI}_{50}$ value in the low micromolar range $(3.88$ $\mu \mathrm{M})$.

On the other hand, insertion of a methyl group on the imidazole resulted in a strong increase of activity for the derivatives $\mathbf{7 a}, \mathbf{e}, \mathbf{f}$, where the benzoyl moiety was respectively unsubstituted (7a vs 6a), or functionalized with 4-trifluoromethyl- (7e vs 6e) and 3-chloro-4-fluoro- (7f vs 6f) substituents. The cytotoxic activity was worthily interesting in the case of derivative $7 \mathbf{f}$, the most active of the benzo[b]furan series, where $\mathrm{GI}_{50}$ values on HeLa and MCF-7 tumour cell lines were respectively at 2.14 and $1.55 \mu \mathrm{M}$.

Generally, the biological activity of tested benzo $[b]$ furan derivatives was less influenced by the nature of substituents (both with electron-withdrawing and electron-releasing effects) located on the benzoyl moiety than by the imidazolyl side chains. However, it was evident that the biological activity of the unsubstituted (5a, 6a, and 7a) and of the 4-trifluoromethyl- 
(5e, 6e, and 7e) derivatives, with respect to the other cases, varied in peculiar way along the progression of the synthesis, from the 5-amino-benzo[b]furans to the methyl-imidazolyl sidechain derivatives. Finally, the biological screening of derivative 3 -amino 16, tested in the 50 $0.1 \mu \mathrm{M}$ concentration range on both tumour cell lines, showed no activity, highlighting the crucial importance of the benzoyl moiety for the antiproliferative effect.

\subsubsection{Cell Cycle analysis}

The methyl-imidazolyl side-chain compounds 7a-f were also tested on HeLa cells, in cell cycle perturbation experiments, to evaluate their potential influence on cell-cycle distribution. The flow cytometric analysis was performed after $24 \mathrm{~h}$ of incubation, in order to detect the shifts in cell cycle distribution before a significant amount of cells undergoing apoptosis. The working concentrations were chosen taking into account the $\mathrm{GI}_{50}$ values measured at $48 \mathrm{~h}$.
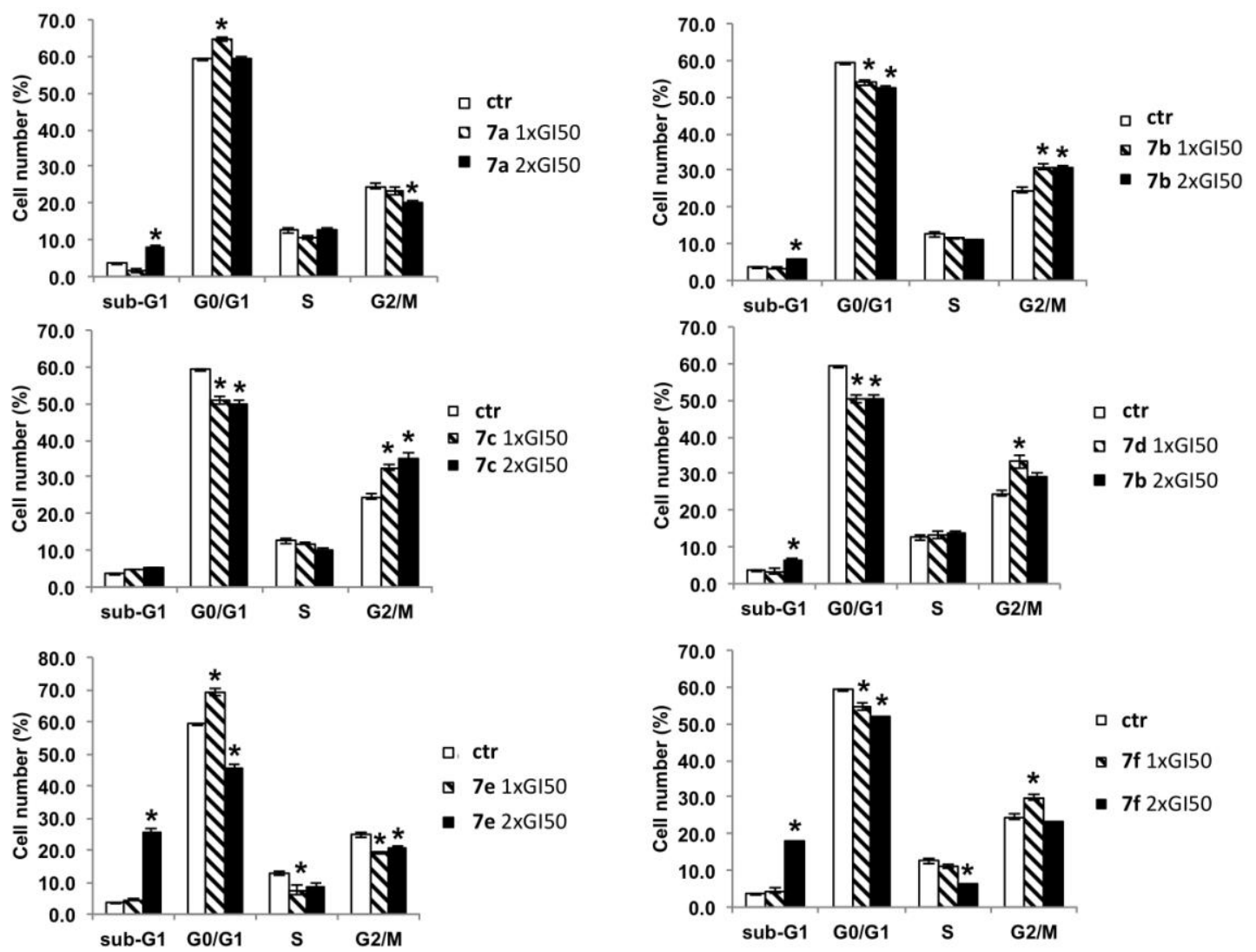

\section{FIGURE 5.}

In Figure 5 the percentage of cells in the respective cell cycle phase (G1, S, and G2/M) were shown, along with the percentage of cells in the sub-G0/G1 (dead cells) detected by flow cytometry. Untreated HeLa cells displayed a normal diploid distribution presenting fast 
proliferation characteristics, with $\mathrm{S}+\mathrm{G} 2 / \mathrm{M}$ cell phases accounting for about $40 \%$ of the total cells (ctrl). Significant suppression of the G0/G1 phase with accumulation of cells in the $\mathrm{G} 2 / \mathrm{M}$ was observed after cell exposure to $1 \mathrm{xGI}_{50} \mu \mathrm{M}$ of methyl-imidazolyl- side-chain derivatives 7b-d,f. The effect was concentration-dependent and, in our experimental conditions, treatment with a concentration of about $2 \mathrm{xGI}_{50}$ produced deep alterations in the distribution profile. In fact, it was possible to observe a significant reduction of the cell number in all phases and a simultaneous increase of the cell population in subG0/G1, which are indicative of apoptotic cells. Interestingly, the unsubstituted 7a and the 4-trifluoromethyl7e derivatives, assayed at $1 \mathrm{x}$ and $2 \mathrm{xGI}_{50}$, failed to produce significant cell cycle alterations. On the contrary, cell exposure to $2.5 \mathrm{xGI}_{50}$ and $5 \mathrm{xGI}_{50} \mu \mathrm{M}$ of derivatives $\mathbf{7 a}$,e, induced G0/G1 arrest associated with reduction of the cell number in other phases.

\subsection{In silico insights}

The structure similarity of the benzo[b]furans $\mathbf{6}, 7$ with colchicine binding site binders 8 and 9, and the evidence of cell cycle arrest in G2/M phase induced by cell exposure to derivatives $\mathbf{7 b - d , f}$, led to hypothesize the interference of these novel compounds with the microtubule system during the cancer cell division processes. This hypothesis was studied by in silico approach, by using ligand based and structure based methods.

In the first case the VLAK protocol was applied with the aim to confirm the hypothesis by molecular descriptors matching through fingerprint virtual screening. As described above the method confirmed that the titled structure posses the chemical-physical characteristic to make them potential tubulin modulators. Moreover, to investigate the binding modes of each derivative in the colchicine binding site of tubulin, in silico structure based method was also approached. In particular Induced Fit Docking protocol (IFD) was approached. ${ }^{[15]}$ It combines molecular dynamics, docking, and MM-GBSA scoring to predict the binding capabilities of ligands versus biological targets. The main aim of IFD protocol was to study the different binding modes of the benzofuran derivatives, taking into account the amino acid residues that are involved in the binding.

This article is protected by copyright. All rights reserved. 


\section{TABLE 3.}

\begin{tabular}{c|ccc}
\hline Title & Prime Energy & Glide gscore & IFDScore $^{[a]}$ \\
\hline $\mathbf{6 a}$ & -34437 & -7.17 & -1729 \\
$\mathbf{6 b}$ & -34462 & -10.51 & -1734 \\
$\mathbf{6 c}$ & -34487 & -11.96 & -1736 \\
$\mathbf{6 d}$ & -34496 & -12.23 & -1737 \\
$\mathbf{6 e}$ & -34480 & -10.45 & -1734 \\
$\mathbf{6 f}$ & -34395 & -11.78 & -1732 \\
\hline $\mathbf{7 a}$ & -34463 & -8.16 & -1731 \\
$\mathbf{7 b}$ & -34481 & -11.04 & -1735 \\
$\mathbf{7 c}$ & -34478 & -10.38 & -1734 \\
$\mathbf{7 d}$ & -34545 & -10.11 & -1737 \\
$\mathbf{7 e}$ & -34371 & -10.53 & -1729 \\
$\mathbf{7 f}$ & -34475 & -11.28 & -1735 \\
\hline COL & -34392 & -10.38 & -1730 \\
\hline CA4 & -34316 & -9.17 & -1725 \\
\hline [a] defined as: Glide Score +0.05 Prime Energy \\
\hline
\end{tabular}

The analysis of calculated values reported in Table 3 displayed that all ligand-tubulin complexes have quite good IFD scores. Particularly, it is evident as the derivatives $\mathbf{6}$ and $\mathbf{7}$ display affinity to the binding site similar to colchicine (COL) and higher than combretastatin A4 (CA4). However when the amino acids involved in the binding complexes were analyzed, significant differences were observed.

Considering the colchicine binding site as a deep pocket placed at the $\alpha-\beta$ interface of tubulin heterodimers it is possible to indentify three main sub-zones involved in the binding complexes. ${ }^{[18,19]}$ The zone 2 is located on the $\beta$ subunit and accommodate the amino acids mainly involved in the colchicine binding complex. The other two zones (zone 1 and zone 3 ) are accessory and respectively located in the $\alpha$ subunit interface and in a deeper cavity of the $\beta$ subunit. ${ }^{[18]}$ In Table 4 the amino acid residues pivotal for the inhibition of tubulin functionality are correlated with the derivatives 6a-f, 7a-f and with the two standards COL, CA4. The orange squares indicate the ligand-tubulin interactions with a distance cut-off of $3 \AA$.

This article is protected by copyright. All rights reserved. 


\section{TABLE 4.}

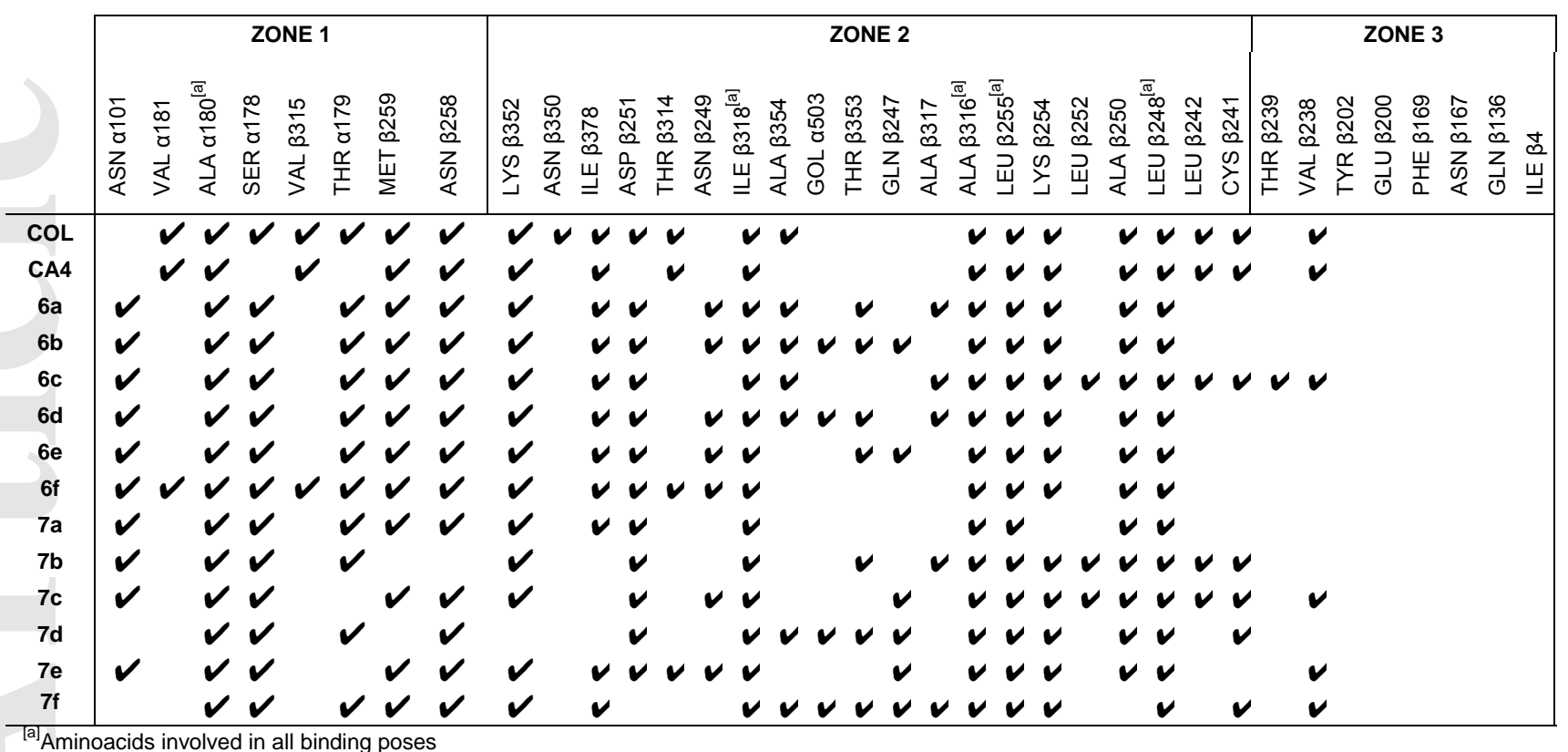

The tested benzofuran compounds showed good interactions with the amino acids ALA $\alpha 180$, SER $\alpha 178$, ILE $\beta 318$, ALA $\beta 316$, LEU $\beta 255$, Leu $\beta 248$ and LYS $\beta 254$, in agreement with the IFD scores. Unlike derivatives $\mathbf{7 a , e}$, the benzo[b]furans $\mathbf{7 b - d , f}$ present an aromatic group in contact with the CYS $\beta 241$, this feature is generally considered to be the most relevant for the identification of new antitubulin molecules, and indeed, the presence of this interaction is often used as a filtering method in docking results. ${ }^{[18]}$ The above mentioned analysis are clearly showed in Figure 6, where the ligand interaction maps of the most representative derivatives $\mathbf{7 b}$ and $\mathbf{7 e}$ are showed and of the reference standard COL (see supplementary material for the full reported ligand interaction maps).

This article is protected by copyright. All rights reserved. 


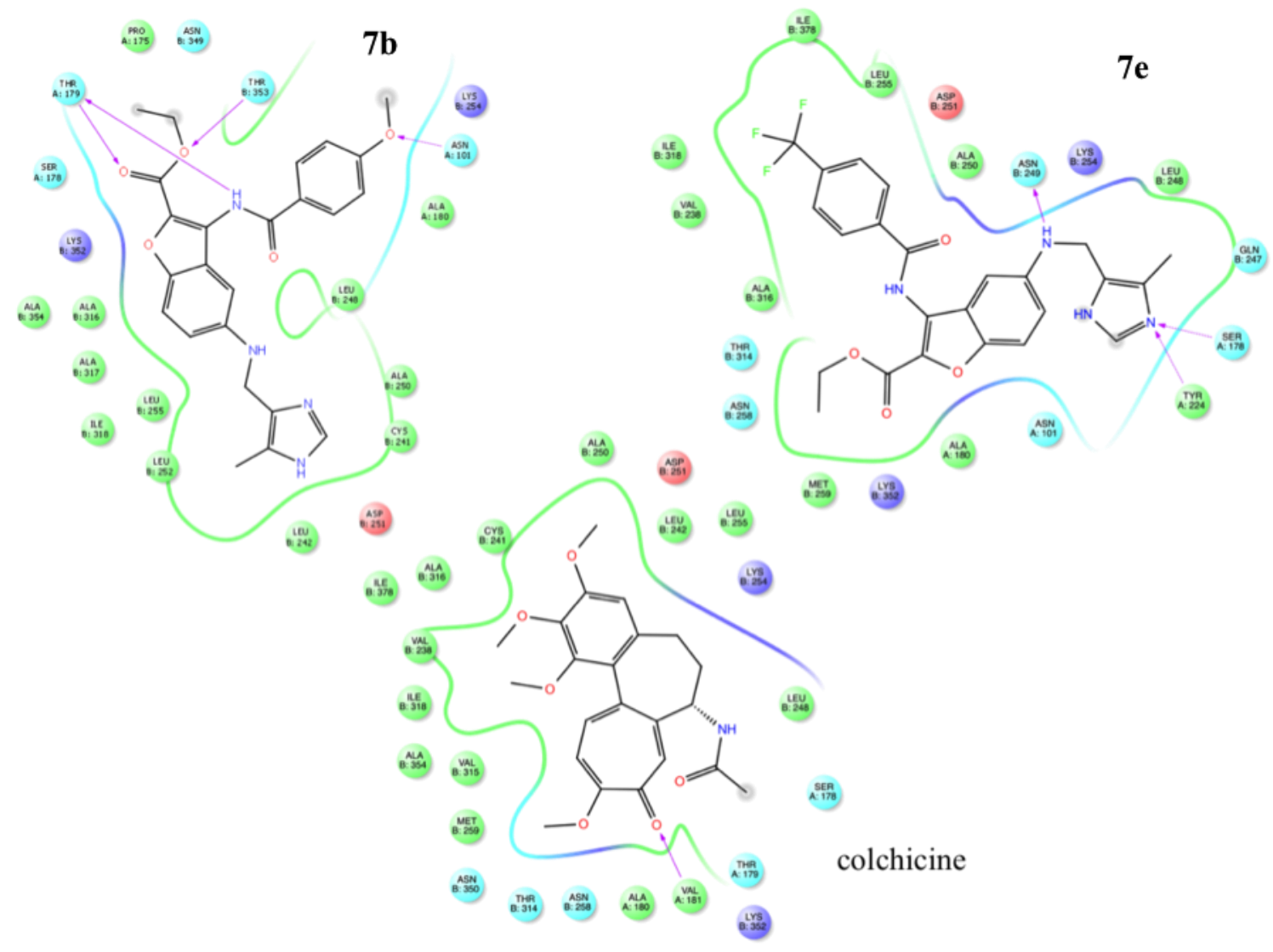

FIGURE 6.

The analysis of the binding modes of the ligands, in the colchicine binding site, showed two different poses. In fact, as depicted in Figure 7 (right, red circle) the the derivatives $7 \mathbf{b}-\mathbf{d}, \mathbf{f}$ have been characterized by the position of imidazolyl- side chain buried in the binding cavity, interacting with the amino acids residues critical for the inhibition of tubulin functionality. On the contrary, the analysis of the derivatives $7 \mathbf{a}, \mathbf{e}$ shows this structural moiety projected outside the cavity (Figure 7, left, red circle), involving, in the ligand-protein complex, amino acids, which are not essential for the antitubulin effect. This behaviour seems consistent with the biological data. In fact, cell cycle perturbation experiments results, that could suggest an antitubulin effect for the derivatives $\mathbf{7 b - d , f}$, were not compatible with an antimitotic mechanism in the other cases. The alternative behaviour of benzofuran compounds could be justified by the presence of different substituents on the benzoyl moiety, which is the only point of diversity among the chemical moieties of the benzofuran derivatives, and for this reason determinant for the orientation in the binding poses.

This article is protected by copyright. All rights reserved. 

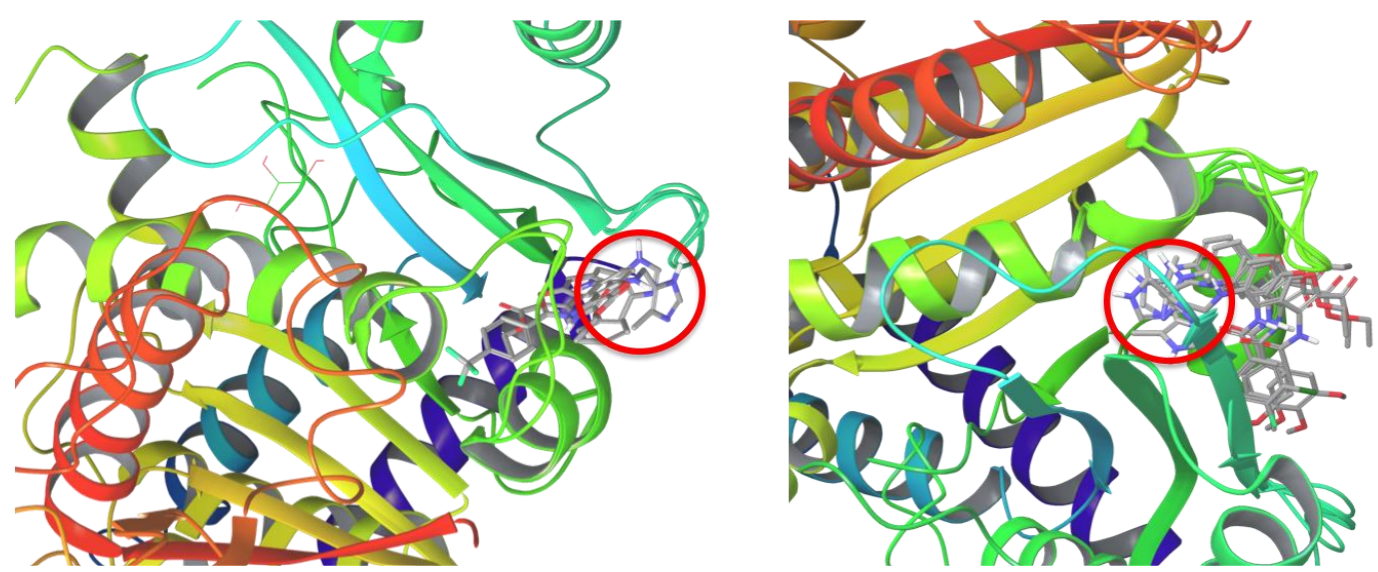

\section{FIGURE 7.}

\section{CONCLUSION}

In this work, the synthesis and the biological evaluation of the new benzo[b]furan series of type 5, 6, and 7 were reported. As a general trend, the antiproliferative screening on HeLa and MCF-7 tumour cell lines underlined a significant growth inhibition effect of final imidazolyl- side chain compounds 6a-f and 7a-f. Methyl insertion on the imidazole ring resulted in a notable increase of activity. The cytotoxic effect is remarkably interesting in the case of derivative $\mathbf{7 f}$, where $\mathrm{GI}_{50}$ values on both HeLa and MCF-7 tumour cell lines are respectively at 2.14 and $1.55 \mu \mathrm{M}$. No differences were observed in the biological activity by changing the substituents on the benzoyl portion, even though the presence of this moiety was crucial for the antiproliferative effects. Indeed, the lack of activity observed through the biological screening of derivative $\mathbf{1 6}$ confirmed the importance of the benzoyl moiety in the benzo[b]furan series. To evaluate their potential influence on cell-cycle distribution, the methyl-imidazolyl- side-chain compounds 7a-f were also tested on HeLa cells, in cell cycle perturbation experiments, producing cell cycle arrest with proapoptotic effects. Their core similarity to known colchicine binding site binders led us to further study by in silico protocols the structure features as antitubulin agents. The results gained from the in silico analysis suggested that other biological targets are involved in the observed biological effects.

\section{ACKNOWLEDGMENTS}

This work was in part supported by an FFR2012 - University of Palermo grant (CUP:B78C12000380001) and by Italian MIUR within the "FIRB-Futuro in Ricerca 2012" Program - Project RBFR12SIPT.

This article is protected by copyright. All rights reserved. 


\section{CONFLICT OF INTEREST}

The authors declare no conflict of interest.

\section{REFERENCES}

[1] A. Lauria, C. Patella, G. Dattolo, A.M. Almerico, J. Med. Chem. 2008, 51, 2037.

[2] A. Lauria, I. Abbate, C. Gentile, F. Angileri, A. Martorana, A.M. Almerico, J. Med. Chem. 2013, 56, 3424.

[3] P. Diana, A. Martorana, P. Barraja, A. Montalbano, A. Carbone, G. Cirrincione, Tetrahedron 2011, 67, 2072.

[4] A. Martorana, A. Pace, S. Buscemi, A.P. Palumbo, Org. Lett. 2012 , 14, 3240.

[5] A. Lauria, M. Tutone, A.M. Almerico, Eur, J. Med. Chem. 2011, 46, 4274.

[6] A. Lauria, C. Patella, I. Abbate, A. Martorana, A.M. Almerico, Eur, J. Med. Chem. 2012, 55, 375 .

[7] A. Lauria, I. Abbate, C. Patella, A. Martorana, G. Dattolo, A.M. Almerico, Eur. J. Med. Chem. 2013, 62, 416.

[8] A. Lauria, C. Patella, I. Abbate, A. Martorana, A.M. Almerico, Eur. J. Med. Chem. 2013, 65, 381 .

[9] A. Martorana, C. Gentile, U. Perricone, A.P. Piccionello, R. Bartolotta, A. Terenzi, A. Pace, F. Mingoia, A.M. Almerico, A. Lauria, Eur. J. Med. Chem. 2015, 90, 537.

[10] H. Khanam, Shamsuzzaman, Eur. J. Med. Chem. 2015, 5, 97, 483.

[11] R. Romagnoli, P.G. Baraldi, M.K. Salvador, F. Prencipe, L.C. Lopez-Cara, S. Schiaffino Ortega, A. Brancale, E. Hamel, I. Castagliuolo, S.Mitola, R. Ronca, R. Bortolozzi, E. Porcù, G. Basso, G. Viola, J. Med. Chem. 2015, 58, 3209.

[12] R. Romagnoli, P.G. Baraldi, M.K. Salvador, D. Preti, M.A. Tabrizi, M. Bassetto, A. Brancale, E. Hamel, I. Castagliuolo, R. Bortolozzi, G. Basso, G.Viola, J. Med. Chem. 2013, 56, 2606.

[13] A.J. Bridges, H. Zhou, J. Het. Chem. 1997, 34, 1163.

[14] T. Mosmann, Methods 1983, 65, 55.

[15] W. Sherman, T Day, M.P. Jacobson, R.A. Friesner, R. Farid, J. Med. Chem. 2006, 49, 534.

[16] T.A. Halgren, R.B. Murphy, R.A. Friesner, H.S. Beard, L.L. Frye, W.T. Pollard, J.L. Banks, J. Med. Chem. 2004, 47, 1750. 
[17] M.P. Jacobson, D.L. Pincus, C.S. Rapp, T.J.F. Day, B. Honig, D.E. Shaw, R.A. Friesner, Proteins: Structure, Function and Bioinformatics 2004, 55, 351.

[18] A. Massarotti, A. Coluccia, R. Silvestri, G. Sorba, A. Bracale, Chem. Med. Chem. 2012, 7, 33 .

[19] Z. Deng C. Chuaqui, J. Singh, J. Med. Chem. 2004, 47, 337.

\section{SUPPORTING INFORMATION}

Additional Supporting Information may be found online in the supporting information tab for this article.

FIGURE 1. Heterocyclic derivatives with outstanding antiproliferative activities.

FIGURE 2. Chemical structures of ethyl 5-amino-3-benzoylamino-benzo[b]furan-2carboxylates 5, and ethyl 3-benzoylamino-5-[(1H-imidazolyl-4-yl-methyl)-amino]benzo[b]furan-2-carboxylates $\mathbf{6}, \mathbf{7}$.

FIGURE 3. Chemical structures of 2-(alkoxycarbonyl)-3-(3,4,5-

trimethoxyanilino)benzo[b]thiophene 8a, 2-(alkoxycarbonyl)-3-(3,4,5-

trimethoxyanilino)thieno[2,3-b]pyridine 8b, 2-(alkoxycarbonyl)-3-(3,4,5-

trimethoxyanilino)benzo[b]furan $\mathbf{9}$, and respectively $\mathrm{IC}_{50}$ ranges against a panel of seven cancer cell lines.

FIGURE 4. Structures of known colchicine binding site binders.

FIGURE 5. Effects of compounds 7a-f on the cell cycle distribution of HeLa cells following $24 \mathrm{~h}$ treatment. The cells were cultured without any compound (ctrl) or with compound used at the indicated concentrations. Cell cycle distribution was analyzed after standard DNAstaining with propidium iodide as described in methods. The histograms represent the percentages of cells in the respective cell cycle phases (G0/G1, S, and G2/M), along with the percentage of cells in the subG1 (dead cells) obtained by flow cytometry. Results are 
expressed as the mean of two independent experiments, performed in duplicate $\pm \mathrm{SE}$. Statistical analyses were performed using the Student's $t$ test to determine the differences between the datasets. ${ }^{*} \mathrm{p}<0.05$ denote significant differences from untreated control cells.

FIGURE 6. Ligand interaction maps of representative derivatives and colchicine.

FIGURE 7. Docking poses of derivatives 7a,e (left) and 7b-d,f (right) in the colchicine binding site (the imidazolyl- side chain moieties are red circled).

SCHEME 1. Synthesis of ethyl 3-benzoylamino-benzo[b]furan-2-carboxylates 5a-f, 6a-f and 7a-f.

TABLE 1. Affinity scores (A\%) calculated by VLAK protocol for the colchicine binding site.

TABLE 2. Antiproliferative activity at $48 \mathrm{~h}$ of 3-benzoylamino-benzo[b]furan derivatives 5af, 6a-f, and 7a-f against HeLa and MCF-7 cell lines expressed as $\mathrm{GI}_{50}$ values $\left[\mathrm{GI}_{50} \pm \mathrm{SE}\right.$ $(\mu \mathrm{M})]$.

TABLE 3. IFD scores of benzofuran derivatives 6, 7, and the reference compounds colchicine (COL) and combretastatin A4 (CA4).

TABLE 4. Summary of the amino acids residues of the colchicine binding site involved in the binding. 